\title{
Identification and localization of collagen types I and IV in the ruminant follicle and corpus luteum
}

\author{
M. R. Luck, Y. Zhao and L. M. Silvester \\ Department of Physiology and Environmental Science, University of Nottingham, Sutton Bonington \\ Campus, Loughborough, LE12 5RD, UK
}

\section{Introduction}

The ovarian cycle is characterized by marked changes in tissue structure and cell function. In particular, the transition from follicle to corpus luteum involves rapid tissue remodelling accompanied by endocrine differentiation. Evidence from several tissues shows that endocrine cell phenotype can be regulated by components of the extracellular matrix (ECM). The speed and intensity of events in the ovary suggest a close relationship between ovarian cells and their extracellular environment (Luck, 1994). Preliminary evidence for this relationship in cows, involving a differential response of luteinizing granulosa cells to various collagen types, has been reported by Luck et al. (1991).

Despite the abundance of collagen in ECMs, its presence in the ovary is poorly described. Little is known about its cellular origin, or its involvement in the transition from follicle to corpus luteum. The follicular basement membrane contains the network collagen type IV (Bertolussi et al., 1989; Luck, 1994), while the fibrillar collagen type I is the most abundant in the corpus luteum (up to $3 \%$ of tissue mass; Luck and Zhao, 1993). Granulosa cells can secrete the components of the basement membrane in culture (Lavranos et al., 1994), but have not been demonstrated to do so in situ. Enzymes regulating collagen turnover are expressed in the mature follicle and early corpus luteum (Freudenstein et al, 1990; Chun et al., 1992; Tadakuma et al., 1993), but the expression of particular collagen types has not been studied. In the study reported here immunological techniques were used to locate specific collagens in ruminant follicles and corpora lutea and the potential for collagen synthesis of particular tissues examined.

\section{Methods}

Ovarian tissues from the mid- to late follicular phase and from the early to late luteal phase were obtained from cows and sheep at slaughter. Cycle stages were determined morphologically (cow; Ireland ef al., 1980), or by reference to prostaglandin synchronization (sheep). Anti-collagen type I antibodies (polyclonal, anti-human; HyClone, UT, and polyclonal, anti-bovine, from D. Hartmann, Institut Pasteur, Lyon), collagen type IV (monoclonal, anti-human and bovine; Sera-Lab, Crawley, Sussex) and von Willebrand factor (vWF; polyclonal, anti-rabbit: Dako, High Wycombe, Bucks.) were used (i) as histochemical markers of cryosectioned tissues, and (ii) in western analysis of SDS-PAGE-separated extracts from follicular fluid, granulosa, basement membrane-theca and corpus luteum tissues. The potential of tissues to synthesize collagen was determined by assaying prolyl-4-hydroxylase activity (Kaule and Günzler, 1990, modified). Briefly, the conversion of 2-oxo[ $\left.{ }^{14} \mathrm{C}\right]$ glutarate (an enzyme cofactor) to $\left[{ }^{14} \mathrm{C}\right]$ succinate was measured in the presence of tissue extract, a specific synthetic substrate ([pro-pro-gly $]_{10}$ polymer) and additional co-factors $\left(\mathrm{Fe}^{2+}\right.$, ascorbate, $\mathrm{O}_{2}$ ).

\section{Results}

As initially predicted, collagen type IV was immunolocated as a discrete band in the follicular basement membrane, separating the theca and granulosa (Fig. Ia). Discontinuous layers were also seen within the 

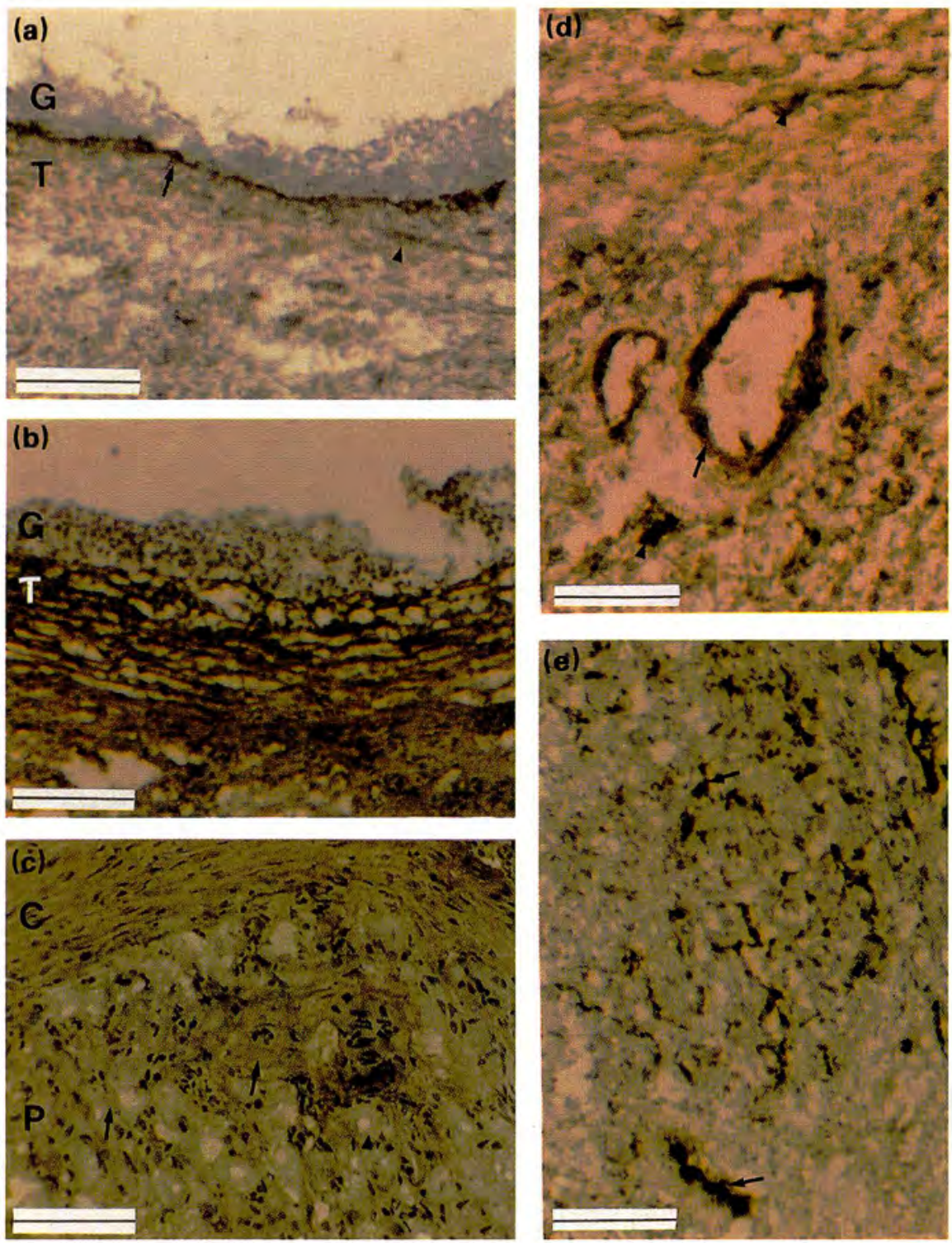

Fig. 1. Immunohistology of ovine ovaries. (a) Follicular tissue (day 4 after ovulation) stained with anti-collagen type IV (dark brown). Basement membrane (arrow) is visible between the granulosa layer $(\mathrm{G})$ and the thecal layers $(\mathrm{T})$ of the follicle wall. Discontinuous staining is also present within the thecal layers (arrowhead). Scale bar $=250 \mu \mathrm{m}$. (b) Follicular tissue day 8 after ovulation stained with anti-collagen type I (brown). Abundant staining of organized layers within the theca $(\mathrm{T})$, parallel to the basement membrane. No staining on antral side. Scale bar represents $100 \mu \mathrm{m}$. (c) Luteal tissue day 4 after ovulation stained with anti-collagen type I (brown). Abundant staining in the capsule (C) surrounding the corpus luteum but also distributed throughout the parenchyma ( $\mathrm{P}$, arrows). Unstained luteal cells are visible (arrowhead). Scale bar $=100 \mu \mathrm{m}$. (d) Luteal tissue day 16 after ovulation stained with anti-collagen type IV. Diffuse staining within the parenchyma (arrowhead) and in association with blood vessels (arrow). Scale bar $=100 \mu \mathrm{m}$. (e) Luteal tissue day 8 after ovulation stained with antivon Willebrand factor (a specific marker for vascular endothelium; black). Diffuse and vessel-associated staining (arrows) visible throughout the parenchyma. Scale bar represents $100 \mu \mathrm{m}$. 


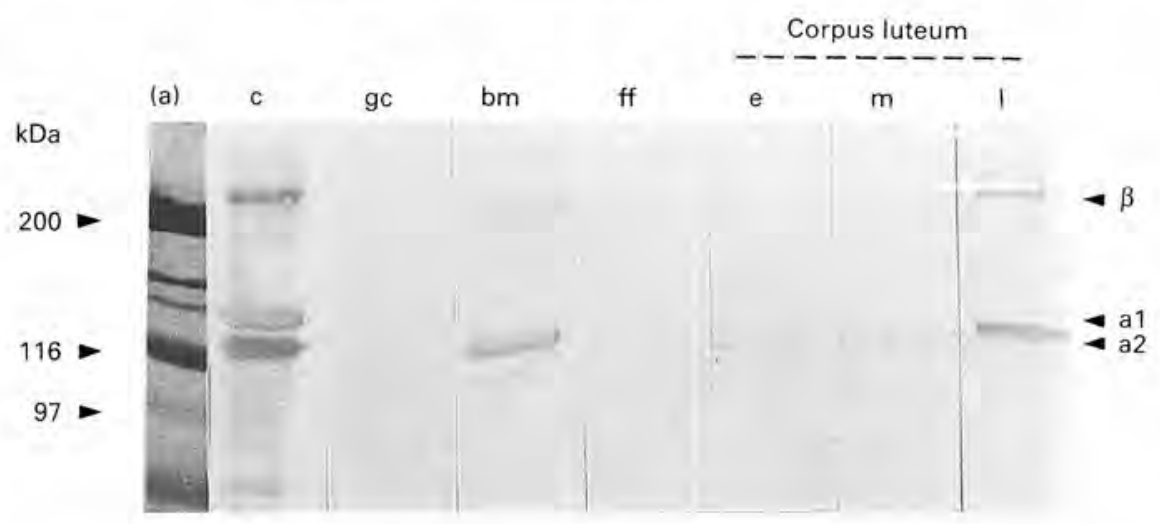

(b)

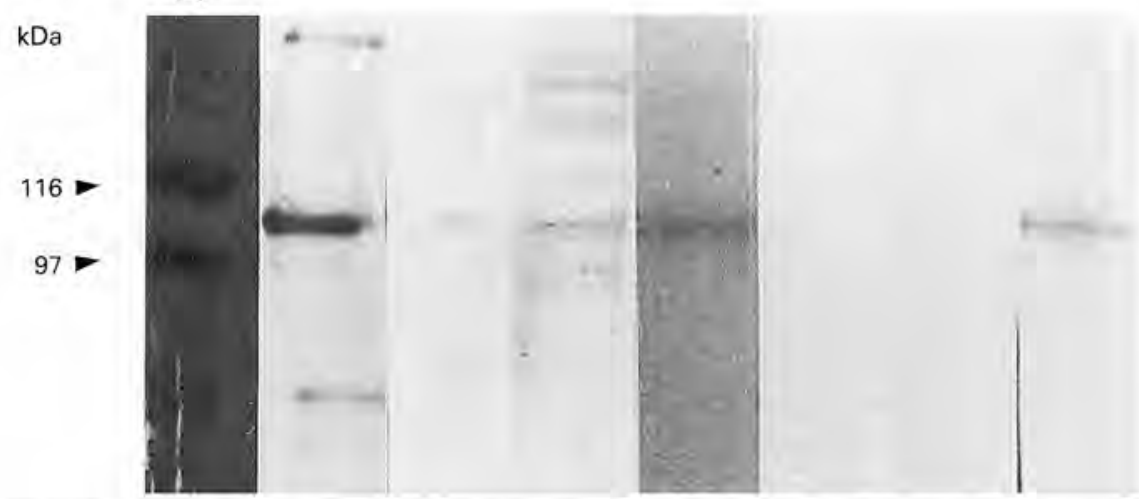

Fig. 2. Western analysis of bovine ovarian protein extracts for (a) collagen type I (non-reducing conditions) and (b) collagen type IV (reducing conditions). Lane 1: molecular mass markers C: purified collagen as reference; gc: granulosa cells; bm: basement membrane-theca; ff: follicular fluid; e: early; $\mathrm{m}$ : middle; l: late.

theca, and occasional fragments of type IV-immunoreactive material occurred in the follicular antrum. No type I immunostaining was seen in the follicular antrum, but it was abundant in the theca and stroma where it formed concentric layers (Fig. 1b). Both types of collagen were detected in sections of corpus luteum but type I was the more abundant, occurring in diffuse structures (Fig. Ic). Type I also formed concentric layers in the extra-luteal stroma (not shown). Type IV appeared in patches within the corpus luteum, as fragments or associated with endothelial structures (Fig. Ic). Fragments were also visible in the extra-luteal stroma, but there were no discrete membranes (not shown). A specific marker of endothelial cells, von Willebrand factor, was also located as a diffuse component of the corpus luteum (Fig. Id).

Western analysis revealed the presence of collagen type I in the basement membrane-theca region of the follicle and in the corpus luteum, but not in the granulosa layer or follicular fluid (Fig. 2a). In contrast, type IV was detected in all follicular regions, with a particularly intense signal in follicular fluid (Fig. 2b). It was also detectable in corpus luteum extracts from the late luteal phase.

Significant prolyl hydroxylase activity was detected in the follicular fluid, granulosa and basement membrane-theca of non-atretic follicles (Fig. 3). The total quantity increased with follicle size during the mid-follicular phase and declined in larger follicles. Its distribution between the tissue fractions changed in favour of the basement membrane-theca as follicles matured. Enzyme activity was also found in corpus luteum tissue, particularly in the early and middle phases (not shown). 

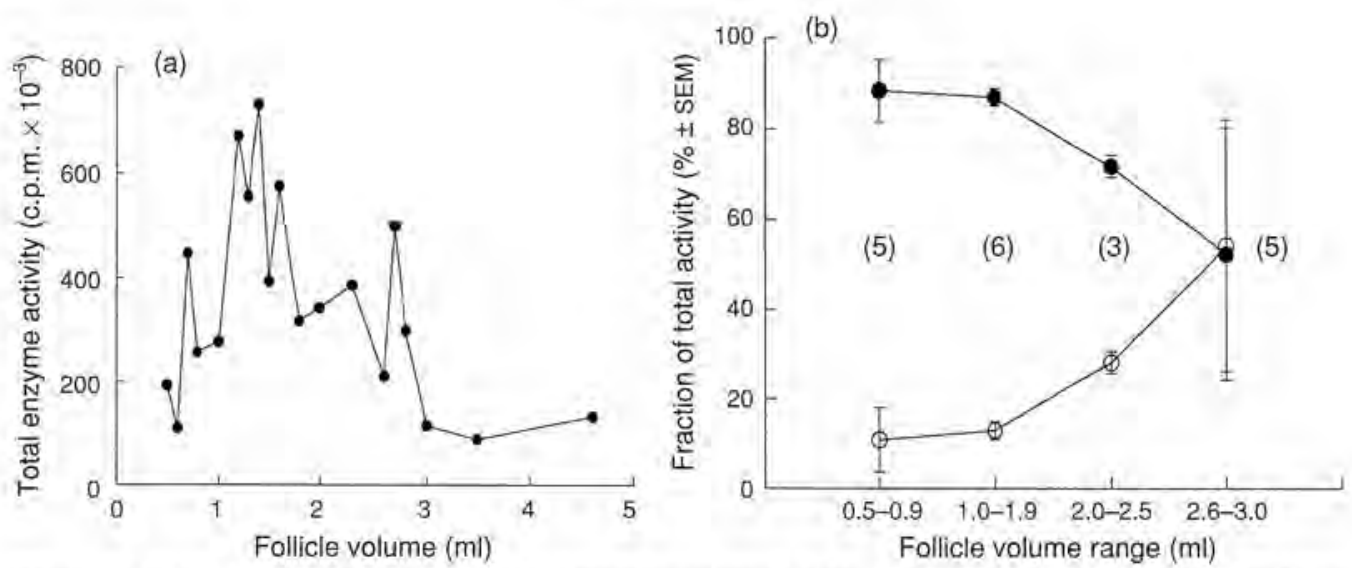

Fig. 3. (a) Prolyl-4-hydroxylase activity $\left({ }^{14} \mathrm{C}\right]$ succinate released) in bovine follicles in relation to fluid volume. (b) Total activity is the sum of activities in (-) follicular fluid and granulosa cells and $(0)$ basement membrane-theca compartments. Numbers in parentheses represent number of follicles.

\section{Discussion}

The data presented here confirm that collagen types I and IV are major structural components of the ruminant follicle and corpus luteum. The tissue-specific localization of individual collagen types is consistent with their proposed role as regulators of cell phenotype during tissue remodelling.

Collagen type IV occurs in the follicular basement membrane but also in tissues on both the thecal and antral sides of the membrane. Its presence in follicular fluid and granulosa, together with significant enzyme activity in these regions, supports the view that the granulosa is involved in basement membrane synthesis (Lavranos ef al., 1994). Since neither the fluid nor the granulosa exhibit a membranous structure, the granulosa-theca interface may be specifically conducive to type IV (membrane) precipitation. Membrane fragments may also be released antrally as a result of basement membrane turnover during follicular growth. The detection of type IV as a diffuse component of the corpus luteum indicates that its synthesis is not confined to the follicle. Although it is possible that fragments of basement membrane persist after ovulation, the similarly diffuse distribution of vWF suggests that much, or all, of this collagen can be ascribed to the luteal endothelium. The corpus luteum has an extensive vasculature (Zheng et al., 1993) and endothelial cells are among the most abundant of luteal cells (Farin et al, 1986).

Collagen type I is the predominant structural collagen of the corpus luteum, synthesized rapidly as the organ develops (Luck and Zhao, 1993). Since type I is absent from the follicular antrum, the post-ovulatory reorganization of the follicle means that this collagen represents a new extracellular surface as far as luteinizing granulosa cells are concerned. Such cells respond to type I in vitro by increasing their expression and synthesis of luteal hormones (Luck et al., 1991). The present observations are therefore consistent with the hypothesis that collagen is an important local regulator of endocrine cell phenotype. The cellular origin of luteal type I remains to be established. Granulosal, thecal and luteal tissues all possess the enzymic machinery for the post-translational hydroxylation of proline, and, therefore, several endocrine and non-endocrine cell types are potential candidates.

\section{Conclusion}

We conclude that collagen types I and IV are major structural components of the ruminant follicle and corpus luteum. Membranes containing type IV occur in the basement membrane and theca, but the protein is also detectable in granulosa cells and follicular fluid. Since these regions also possess prolyl hydroxylase activity, it is likely that the granulosa contributes to the synthesis and turnover of the 
basement membrane during follicle growth. Type IV is also present in the corpus luteum, probably in association with the endothelium. The predominant collagen of the corpus luteum is type I, synthesized as the tissue develops. Since type I is absent from the follicular antrum, this represents a new ECM protein as far as granulosa-derived cells are concerned. The presence of type I collagen in the developing corpus luteum is consistent with its ability to support granulosa luteinization.

Supported by the Wellcome Trust.

\section{References}

Bertolussi M, Zanchetta R, Doliana R, Castellani I, Bressan GM and Lauria A (1989) Changes in the organization of the extracellular matrix in ovarian follicles during the preovulatory phase and atresia: An immunofluorescence study Basic and Applical Histochemistry $333 \mathrm{I}-3 \mathrm{~B}$

Chun SY, Popliker M, Reich R and Tsafriri A (1992) Localization of preovulatory expression of plasminogen activator inhibitor type-I and tissue inhibitor of metalloproteinase type-I mRNAs in the rat ovary Biology of Reproduction 47 245-253

Farin $\mathrm{CE}_{\text {, Moeller }} \mathrm{CL}_{1}$ Sawyer HR, Gamboni $\mathrm{F}$ and Niswender GD (1986) Morphometric analysis of cell types in the ovine corpus luteum throughout the estrous cycle Biology of Reproduction 35 1299-1308

Freudenstein J, Wagner S, Luck MR, Einspanier R and Scheit KH (1990) mRNA of bovine tisue inhibitor of metalloproteinase: sequence and expression in bovine ovarian tissues Biochemical and Biophysical Research Comminications 171 250-256

Ireland J, Murphee RL and Coulson PB (1980) Accuracy of predicting stages of bovine oestrous cycle by gross appearance of corpus luteum Jonitial of Dairy Science 63 $155-160$

Kaule G and Güzler V (1990) Assay for 2-oxoglutarate decarboxylating enzymes based on the determination of
[1. $\left.{ }^{14} \mathrm{C}\right]$ succinate: application to prolyl-4-hydroxylase Analytical Biochemistry 184 291-297

Lavranos TC, Rodgers HF, Bertoncello I and Rodgers RJ (1994) Anchorage-independent culture of bovine granulosa cells: the effects of basic fibroblast growth factor and dibutyryl CAMP on cell division and differentiation Experimental Cell Research 211 245-251

Luck MR (1994) The gonadal extracellular matrix Oxford Revietes of Reproductive Biology 16 33-85

Luck MR and Zhao Y (1993) Identification and measurement of collagen in the bovine corpus luteum and its relationship with ascorbic acid and tissue development Joumal of Reproduction and Fertility $99647-652$

Luck MR, Munker M and Praetorius C (1991) Autocrine control of phenotype by extracellular matrix proteins in luteinizing granulosa cells Journal of Reproduction and Fertility Supplement 43 101-107

Tadakuma H, Okamura H, Kitaoka M. Iyama K and Usuku GA (1993) Association of immunolocalization of matrix metalloproteinase 1 with ovulation in hCG-treated rabbit ovary Joumal of Reproduction and Fertility 98 503-508

Zheng J, Redmer DA and Reynolds LP (1993) Vascular development and heparin-binding growth factors in the bovine corpus luteum at several stages of the estrous cycle Biology of Reproduction 49 i177-1189 